\title{
Divergent, plausible, and relevant climate futures for near- and long-term resource planning
}

\author{
David J. Lawrence ${ }^{1}$ (D) Amber N. Runyon ${ }^{1}$ (D) $\cdot$ John E. Gross ${ }^{1}$ (D) \\ Gregor W. Schuurman ${ }^{1}$ (D) Brian W. Miller ${ }^{2}$ (D)
}

Received: 4 January 2021 / Accepted: 7 July 2021/ Published online: 13 August 2021

(C) This is a U.S. government work and not under copyright protection in the U.S.; foreign copyright protection may apply 2021

\begin{abstract}
Scenario planning has emerged as a widely used planning process for resource management in situations of consequential, irreducible uncertainty. Because it explicitly incorporates uncertainty, scenario planning is regularly employed in climate change adaptation. An early and essential step in developing scenarios is identifying "climate futures"-descriptions of the physical attributes of plausible future climates that could occur at a specific place and time. Divergent climate futures that describe the broadest possible range of plausible conditions support information needs of decision makers, including understanding the spectrum of potential resource responses to climate change, developing strategies robust to that range, avoiding highly consequential surprises, and averting maladaptation. Here, we discuss three approaches for generating climate futures: a Representative Concentration Pathway (RCP)-ensemble, a quadrant-average, and an individual-projection approach. All are designed to capture relevant uncertainty, but they differ in utility for different applications, complexity, and effort required to implement. Using an application from Big Bend National Park as an example of numerous similar efforts to develop climate futures for National Park Service applications over the past decade, we compare these approaches, focusing on their ability to capture amongprojection divergence during early-, mid-, and late-twenty-first century periods to align with near-, mid-, and long-term planning efforts. The quadrant-average approach and especially the individual-projection approach captured a broader range of plausible future conditions than the RCP-ensemble approach, particularly in the near term. Therefore, the individual-projection approach supports decision makers seeking to understand the broadest potential characterization of future conditions. We discuss tradeoffs associated with different climate future approaches and highlight suitable applications.
\end{abstract}

David J. Lawrence

david_james_lawrence@nps.gov

1 Climate Change Response Program, National Park Service, Fort Collins, CO, USA

2 U.S. Geological Survey, North Central Climate Adaptation Science Center, Fort Collins, CO, USA 
Keywords Climate adaptation $\cdot$ Climate change $\cdot$ Climate futures $\cdot$ Climate projection $\cdot$ Resource management $\cdot$ Scenario planning

\section{Introduction}

Resource management planning in the face of rapid anthropogenic climate change is fundamentally challenging due to irreducible uncertainties in climate projections and responses by ecological and social systems. In this planning environment, a decision maker's goal is often to minimize failure, rather than maximize success. This goal applies especially to avoiding costly and often catastrophic "surprises" (negative outcomes that were not considered; Terando et al. 2020) driven by climate change and complex interactions between nature and humans (Kopp et al. 2017). In these circumstances, scenario planning has emerged as a widely used planning process that acknowledges and incorporates this uncertainty and provides a way to identify and avoid potential surprises (Brekke et al. 2009a; Gross et al. 2016; Lempert et al. 2003; Peterson et al. 2003; Star et al. 2016). Scenario planning originated in the military and business sectors but has been increasingly applied in the field of conservation planning and climate change adaptation. For planning purposes, scenarios should be plausible (i.e., science-based) and challenging pictures of the future that encapsulate key uncertainties and system responses (Rowland et al. 2014). A key benefit of explicitly engaging this uncertainty is that it helps decision makers identify strategies robust to a wide range of potential futures, including those with low-probability, high-consequence events (Brekke et al. 2009a). Furthermore, by considering a range of plausible futures and time frames, managers can evaluate near- and longterm consequences of actions and identify contingencies that may provide or deny future opportunities. A full consideration of multiple futures also diminishes the role of climate "prediction," reducing the need for, and focus on, deterministic or over-optimized adaptation strategies that only work if the prediction is correct (Carbone 2014; Dessai et al. 2009).

In the context of planning for climate change, an early and essential step in developing plausible scenarios is to identify the "climate futures" (CFs, hereafter) - divergent descriptions of the physical attributes of climate that could plausibly occur at a specific place and time in the future. CFs characterize uncertainty and are foundational to scenarios of climate change implications (Fig. 1a). Divergent CFs that describe the broadest possible range of plausible conditions support information needs of decision makers, including understanding the spectrum of potential resource responses to climate change, developing strategies robust to that range, avoiding highly consequential surprises, and averting maladaptation. Plausible future climates are derived from global climate models (GCMs), typically driven by different greenhouse gas (GHG) emission pathways. Pathways of GHG emissions have been standardized as a set of Representative Concentration Pathways (RCPs; Moss et al. 2010) that reflect the climate consequences of a broad range of socio-economic futures and have been accepted by the international community. A large set of GCMs, reflecting different quantitative representations of atmospheric dynamics and different sets of Earth system processes, have used these standardized RCPs to generate climate projections through the twenty-first century. By representing a range of climate forcings (i.e., RCP 2.6, RCP 4.5, RCP 6.0, RCP 8.5), effectively from low to high, these RCPs provide a convenient means for building scenarios. For example, a "least-change" scenario would average the results from GCMs driven by RCP 2.6, which reflects the least change in GHG concentrations from current levels, to explore the potential effects of climate change on resources of concern. By contrast, a "most change" 
(a)

Climate Future
A description of the
physical attributes of
climate that could plausibly
occur at a specific place
and time in the future.
Useful climate futures
focus on climate metrics
that are relevant to
resources or decisions.
Typically, multiple climate
futures are used to
consider the range of ways
climate could change.

(b)

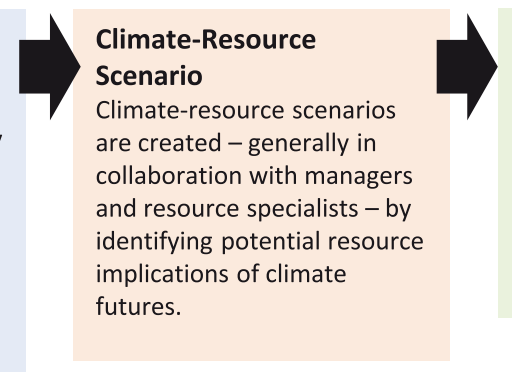

Decision Making

Decisions are developed and tested using the climateresource scenarios. The goal is to use the scenarios to inform and test actions and management decisions and feed them into planning.
The Chisos Basin in Big Bend National Park under a Hot Dry climate future is projected to experience a $5.2^{\circ} \mathrm{C}$ increase in annual temperature and a 113 $\mathrm{mm}(-31 \%)$ decline in annual precipitation during the period 2050-2080 (ca 2065).

Under a Warm Wet climate future the Chisos Basin annual temperature increases $1.2^{\circ} \mathrm{C}$, with a 89 $\mathrm{mm}(+25 \%)$ increase in annual precipitation during the period 2050-2080 (ca 2065).
The Hot Dry climate future

results in a climate-resource scenario with reduced discharge from Oak Spring, a shallow groundwater spring that serves as the sole water supply to the Chisos Basin developed area. Under this scenario the number of months per decade that Oak Spring flows fall below a critical threshold in the 2060 s is more than double the historical average.

For the Warm Wet climate future, although the annual precipitation increases, so does the interannual variability in annual precipitation. This results in a climate-resource scenario where the number of months per decade that Oak Spring flows fall below a critical threshold in the 2060s is similar to the historical baseline.

\section{1} Based on the two climateresource scenarios, park management decided to undertake measures to proactively enhance the reliability of Oak Spring as a water source into the future, including work to (1) use water more efficiently, (2) improve infrastructure to decrease water loss due to leaks, and (3) increase the storage capacity of water tanks that temporarily store Oak Spring water so that it is available in drought periods.

Fig. 1 a Role of CFs in supporting scenario-based climate adaptation. The scenario planning process (only a portion of which is shown here) includes the development of CFs, addition of resource implications (i.e., vulnerabilities) to create climate-resource scenarios, and, ultimately, application in decision making. b Example CFs from the Big Bend National Park water development decision process for the Chisos Basin illustrates the steps in the process. Figure modified from Runyon et al. (2020)

scenario would average projections from RCP 8.5 , which reflects the greatest increase in GHG emissions.

Although many climate assessments have relied on RCP-based scenarios (Jantz et al. 2016; Monahan et al. 2013; Ryan et al. 2020; van Hooidonk et al. 2015; Whitlock et al. 2017)including those conducted to support US National Park Service (NPS) resource 
management - this approach has a number of shortcomings, particularly for near-term planning. A key issue of developing scenarios around RCPs is they fail to fully characterize uncertainty for the next 30 years in the future because atmospheric $\mathrm{CO}_{2}$ concentrations are similar for all RCPs until about 2050 (Kirtman et al. 2013). The considerable variation in nearto mid-term climate projections is primarily due to natural climatic variation and differences in the response of GCMs to the same radiative forcings and not GHG concentrations (Hawkins and Sutton 2009). Local, state, tribal, and federal organizations commonly focus on near-term planning, and thus, a mismatch exists between the need to understand the full range of plausible climatic conditions within the planning horizon and the capacity of RCP-centered approaches to capture that range. To support near-term decisions by NPS managers, we needed an efficient, consistent, and effective means to identify CFs for routine park planning. RCPbased CFs did not meet our needs for CFs that were plausible, relevant, and that adequately captured the range of potential climatic conditions under both near- and longer-term horizons.

Here, we examine three approaches to generate divergent CFs to support decision makers' needs. All three processes are designed to capture the relevant uncertainty for a given management application, but they vary in detail, complexity, and effort and are scaled to meet a range of information needs. Using an application from Big Bend National Park (BBNP, hereafter) as an example of numerous similar efforts to develop CFs for NPS applications over the past decade (see NPS 2021), we describe how different degrees of among-projection divergence are captured with each approach. To do so, we compared the range of uncertainty captured by the different CF approaches during early (2040s), mid- (2060s), and late twentyfirst century (2080s) periods to align with near-, mid-, and long-term planning efforts. We also describe key considerations when developing CFs, including tradeoffs inherent in each approach.

\section{Case study application of climate futures-Big Bend National Park}

CFs generated for BBNP were used to evaluate future projections of groundwater discharge from Oak Spring, a key groundwater-fed spring that serves as the sole water source for the Chisos Basin (latitude 29.278, longitude -103.337), one of the busiest areas of the park (Lawrence and Runyon 2019). Contemporary precipitation is a key driver of Oak Spring recharge, so changes in precipitation are anticipated to have direct and immediate implications for this water source (Lawrence and Runyon 2019). At the same time, the infrastructure that supports water acquisition and delivery from Oak Spring is about 70 years old and needs replacement. Therefore, park managers were interested in evaluating future projections of the recharge and discharge for Oak Spring to determine risks and benefits associated with three potential actions: (1) re-developing the Oak Spring water supply system as is, (2) redeveloping the Oak Spring system but reconfiguring it to withstand longer and more severe dry periods, or (3) switching to another water source with older, deeper groundwater, i.e., a water supply presumed to be less sensitive to contemporary climate conditions. The design life of the re-development project was 50-70 years and the range in cost associated with these different options was substantial ( $\$ 8 \mathrm{M}$ to $>\$ 10 \mathrm{M}$; source-switching [option 3] being the most expensive). Given the desired longevity of this large investment, a major consideration in choosing among the different actions was future climate conditions, making the value of CFs significant to this decision. CFs were generated from projections of precipitation and air temperature (which can influence available water due to evapotranspiration processes, details 
below). Resource managers were ultimately interested in evaluating how often Oak Spring discharge may fall below 20 gal per minute (gpm) in the future (compared to the past). This threshold challenges water operations for the park and may invoke a drought water conservation plan. Alternative approaches (e.g., decision scaling (Brown et al. 2012), stress testing (Albano et al. 2021)) could also be used to get at this question, especially when clear performance thresholds or risks can be related directly to climate. However, scenario planning often addresses a diversity of resources, and for many of the resources the NPS manages, defining thresholds or discrete events would be difficult. Therefore, a scenario planning approach that does not necessarily rely on them is useful.

\section{Generating climate futures}

CFs for BBNP were derived from daily projections of precipitation and temperature for a 16$\mathrm{km}^{2}$ grid cell overlaying the primary recharge area for Oak Spring. From this grid cell, twenty GCMs from the Coupled Model Intercomparison Project Phase 5 archive were used (CMIP5; Taylor et al. 2012), statistically downscaled using the Multivariate Adaptive Constructed Analog method (MACAv2-METDATA; Abatzoglou and Brown 2012). We used results for GCMs driven by RCP 4.5 and RCP 8.5. CFs were generated using the 30-year climate normal convention (e.g., a ca. 2040 CF represents data summarized over the period 2025-2055). These CFs were compared to the historical period 1950-1999. We chose this period because key statistical properties of the MACAv2-METDATA precipitation data matched the observed record only over a longer, 50-year period. Given the multitude of GCM projections (twenty GCMs driven by two RCPs would represent 40 different plausible CFs; Fig. 2a), here we review three approaches to capture the range of projections with a more tractable set of representative CFs. These approaches include RCP-based ensembles, quadrant-average, and individual GCM projections (hereafter referred to as the RCP, quadrant, and individualprojection approaches, respectively). The term "projection" refers to a climate model (e.g., IPSL-CM5A-MR) driven by a specific radiative forcing (e.g., RCP 4.5).

CFs that use the RCP approach are typically developed by averaging climate metrics from all or a subset of GCMs for selected RCPs-often a high emissions scenario and a mid-range mitigation scenario (RCP 8.5 and RCP 4.5; USGCRP 2018). In this approach, divergence among the CFs primarily represents uncertainty regarding societal GHG emissions (Fig. 2b). The quadrant and individual-projection approaches begin by plotting deviations of projected climate metrics from a historical-period average, with each point representing a projection from a GCM-RCP combination (Fig. 2c, d). Results from GCMs driven by different RCPs are plotted together, to fully represent both model and emissions uncertainty (Fig. 2a). The axes may be simple metrics, such as change in average annual temperature and precipitation, or more complex derived indices associated with specific resource sensitivities (see Section 5.3 for more detail).

In the quadrant approach, the scatterplot is divided into quadrants using the mean value of each axis. These quadrants are further refined by defining and excising the central tendency, defined here as the 25th-75th percentile of change for each axis (box in center of Fig. 2c). The average values of all or a subset of projections in each sub-quadrant are used to represent a CF (Fig. 2c). For example, the upper left subquadrant of Fig. 2c characterizes a "Warm Wet" future with increasing temperature and precipitation compared to the historical period. The lower right sub-quadrant is 
(a) Projections

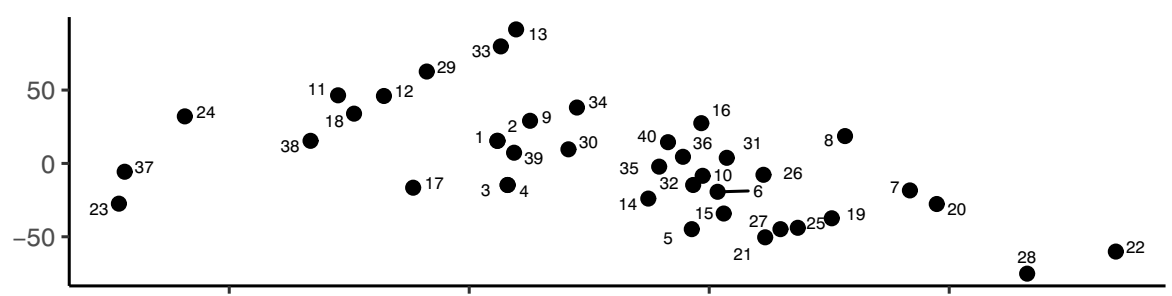

(b) RCP

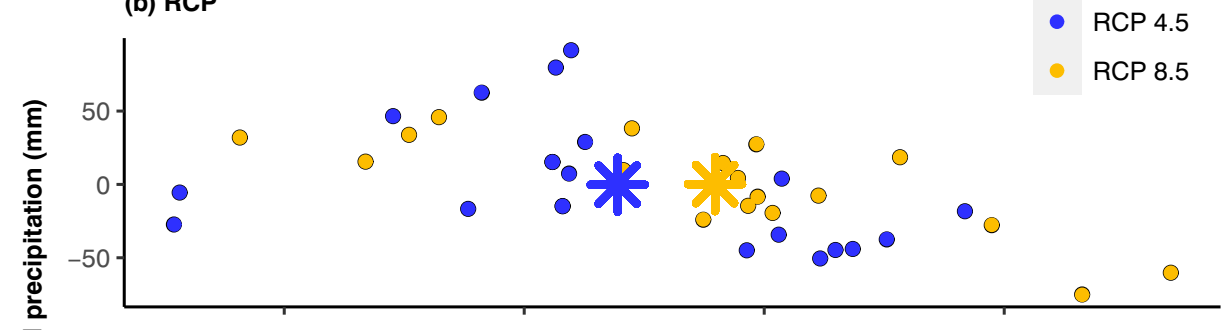

(c) Quadrant

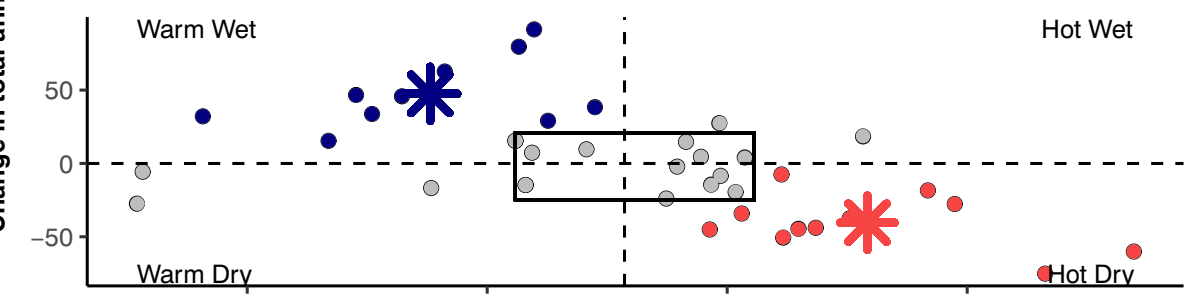

(d) Individual projection

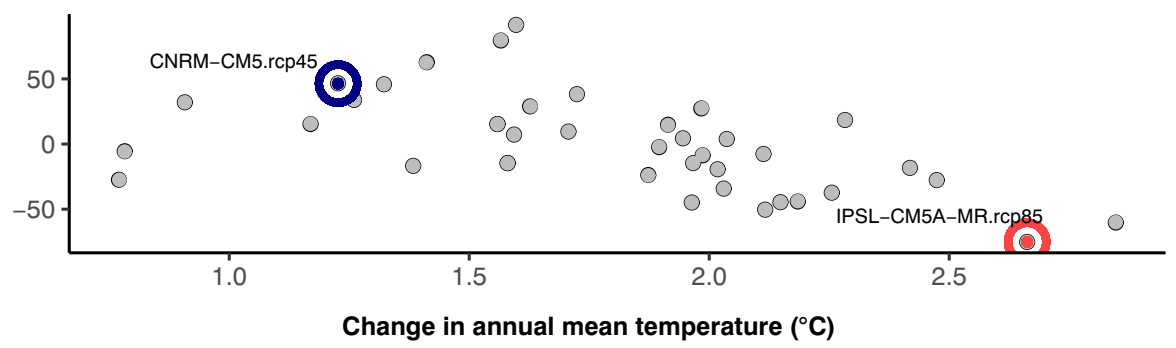

Fig. 2 Change in average annual mean temperature and average annual total precipitation ca. 2040 (2025-2055) relative to the 1950-1999 historical period for the Chisos Basin, Big Bend National Park for a each GCM-RCP projection, with corresponding model names in Table S1, b RCP ensemble-based CFs based on RCP 4.5 (blue) and RCP 8.5 (yellow) projections (asterisks represent the ensemble [i.e., the average of projections] for RCP 4.5 and RCP $8.5 \mathrm{CFs}$ ), c quadrant-based CFs (blue and red points represent "Warm Wet" and "Hot Dry" projections, respectively; asterisks represent "Warm Wet" and "Hot Dry" CF ensemble means, determined by averaging blue and red projections within the sub-quadrant), and $\mathbf{d}$ Individual-projection-based CFs (CNRM-CM5 RCP 4.5 and IPSL-CM5A-MR RCP 8.5). For $\mathbf{c}$, dashed lines indicate the mean value of all projections for each axis and the box indicates the central tendency encompassing the 25th and 75th percentiles for each axis. Projections can be characterized as "Warm Wet," "Hot Wet," "Hot Dry," and "Warm Dry" CFs according to sub-quadrant (upper left, upper right, bottom right, and bottom left sub-quadrants, respectively); in c, we highlight one example CF contrast ("Warm Wet" versus "Hot Dry"), but other CF contrasts could be used. Gray points in $\mathbf{c}$ and $\mathbf{d}$ represent unused projections in the development of those climate futures 
most divergent from this "Warm Wet" future and, because projections in this subquadrant have larger increases in temperature and a reduction in precipitation compared to the historical period, these projections characterize a "Hot Dry" CF. The upper right ("Hot Wet") and lower left ("Warm Dry") sub-quadrants represent other potential divergent CFs. The quadrant approach was adapted from the Volpe Center climate futures exploration and synthesis approach (Rasmussen et al. 2015).

The individual-projection approach selects projections to capture maximal divergence in the metrics selected for the scatterplot axes. Quadrants and sub-quadrants can be used as a guide for selecting individual projections for this approach, but quadrants are not always useful, such as when projections are unevenly distributed across quadrants and instead form a linear or triangular "cloud" of points. In the BBNP application, individual projections were used to characterize a divergent "Warm Wet" and "Hot Dry" CF pair (Fig. 2d). When more than two climate metrics are used to define CFs, projections that provide the greatest divergence across those multivariate projections are chosen (e.g., Schuurman et al. 2019; Section 5.3). Where possible, individual projections should be vetted for a geography before they are relied upon to represent a plausible $\mathrm{CF}$, at least to the extent that GCMs known to underperform in a particular region are avoided (Karmalkar et al. 2019; Littell et al. 2011). Some tools and evaluations can help assess model performance for a given geography (Bock et al. 2018; Rupp et al. 2013; Sheffield et al. 2013a; Sheffield et al. 2013b).

The quadrant and individual-projection approaches capture uncertainty stemming from GCMs and RCPs without differentiating between the two sources, which is useful for the scenario planning context focused on capturing the broadest range of plausible conditions. Treating this uncertainty together has precedent in the literature (Battaglin et al. 2020; BOR 2014; Hay and McCabe 2019; Maloney et al. 2020).

\section{Comparing methodologies for capturing the range of uncertainty over three time periods}

To illustrate differences in the range of uncertainty captured using RCP, quadrant, and individual-projection CF approaches, we evaluated the divergence of each approach for near-, mid-, and long-term planning purposes at BBNP.

Figure 3 illustrates future changes in temperature and precipitation for BBNP's Chisos Basin, using forty GCM-RCP projections (20 GCMs driven by RCPs 4.5 and 8.5) for three periods centered on 2040, 2060, and 2080. All projections indicate the future will be warmer than the past. In the nearest time frame (2040), there is almost complete overlap in temperature from GCMs driven by RCP 4.5 and RCP 8.5 (Fig. 3a), with the overlap diminishing through time (Fig. 3b, c). Precipitation projections for the Chisos Basin are uncertain-specifically, some indicate precipitation increases whereas others indicate decreases - in all time periods. Unlike temperature projections that sort according to RCP in the 2060s and 2080s (RCP 8.5 warmer than RCP 4.5), there is no indication of systematic increases or decreases in annual precipitation associated with a given RCP throughout the projection period (2025-2095). Therefore, for precipitation, the GCMs themselves, rather than the RCPs, drive amongprojection divergence (Fig. 3). In other areas, such as the Arctic and high latitudes, both temperature and precipitation trends are consistently and strongly associated with GHG emissions (IPCC 2013). 
(a) 2040

- RCP 4.5

$100-10-\begin{aligned} & \text { Warm } \\ & \text { Wet }\end{aligned}$

RCP 8.5
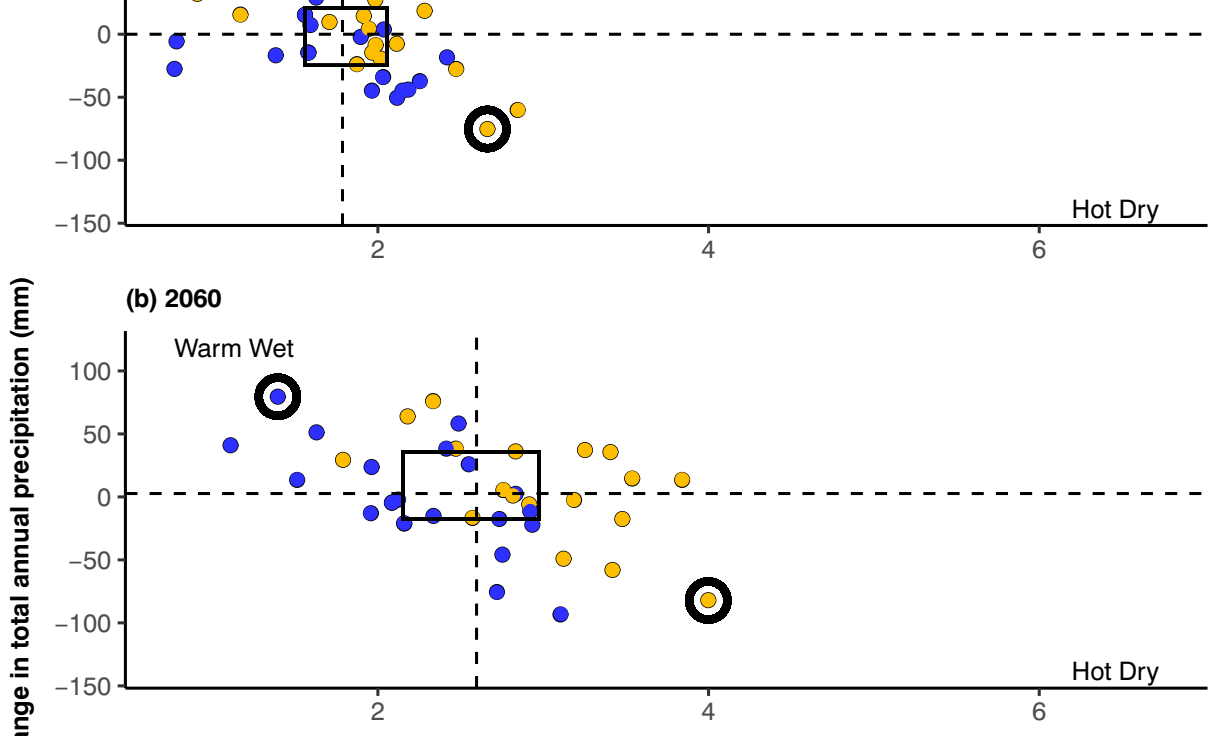

(c) 2080

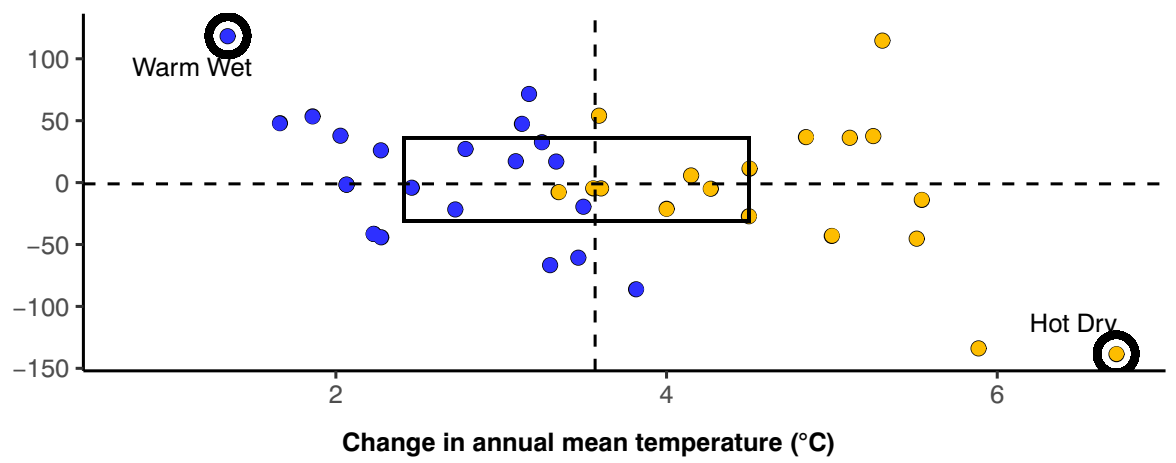

Fig. 3 Change in average annual mean temperature and average annual total precipitation ca. a 2040 (20252055), b 2060 (2045-2075), and c 2080 (2065-2095), relative to the 1950-1999 historical period for each GCMRCP projection in the Chisos Basin, Big Bend National Park. Models driven by RCP 4.5 and 8.5 are represented by blue and yellow points, respectively. Dashed lines indicate the mean value of all projections for each axis and the box indicates the central tendency encompassing the 25 th and 75 th percentiles for each axis. The circled models include CNRM-CM5 RCP 4.5 (blue, 2040), GFDL-ESM2M RCP 4.5 (blue, 2060), INM-CM4 RCP 4.5 (blue, 2080), IPSL-CM5A-MR RCP 8.5 (yellow, all periods)

For the quadrant and individual-projection approach, we focused on a "Hot Dry" and "Warm Wet" CF pair to investigate decision-relevant uncertainty in how Oak Spring may respond to climate change. These CFs were intended to characterize divergent worst-case ("Hot Dry") and best-case ("Warm Wet") futures. For the quadrant approach, the "Hot Dry" and "Warm Wet" CFs intermingle GCMs driven by RCP 4.5 and 8.5 for the 2040 and 2060 periods, whereas the RCPs are largely segregated on the temperature (but not precipitation) axis by the 2080 period (Fig. 3). 
Table. 1 Example climate futures for Big Bend National Park and evaluation of the range of uncertainty captured using RCP, quadrant, and individual-projection climate future approaches. a average annual mean temperature and $\mathbf{b}$ average annual total precipitation for three time periods (ca. 2040, 2060, 2080) for RCP 8.5 and RCP 4.5 ensemble models, quadrant average-based CFs ("Hot Dry," "Warm Wet"), and individual GCM-RCP projections. For individual "Hot Dry" projections IPSL-CM5A-MR RCP 8.5 was used to represent the hottest, driest projection for all periods because it was consistently the driest projection across all periods. For individual "Warm Wet" projections the following models were used to represent a characteristically warm, wet projection for each time period: 2040, CNRM-CM5 RCP 4.5; 2060, GFDL-ESM2M RCP 4.5; 2080, INM-CM4 RCP 4.5. Time periods represent 30-year averages; 2025-2055 (2040), 2045-2075 (2060), and 2065-2095 (2080). The ranges refer to the divergence between the different CFs (e.g., RCP 8.5 vs 4.5) for temperature and precipitation based on the climate future approach. The percentage represents the range of uncertainty of the RCP or quadrantapproach relative to the individual-projection approach

\begin{tabular}{llll}
\hline (a) Temperature $\left({ }^{\circ} \mathrm{C}\right)$ & 2040 & 2060 & 2080 \\
RCP 8.5 & 20.1 & 21.2 & 22.8 \\
RCP 4.5 & 19.9 & 20.5 & 20.9 \\
RCP approach range & $0.2(14.3 \%)$ & $0.7(26.9 \%)$ & $1.9(35.2 \%)$ \\
Hot Dry & 20.5 & 21.3 & 23.6 \\
Warm Wet & 19.6 & 20.1 & 20.6 \\
$\quad$ Quadrant approach range & $0.9(64.3 \%)$ & $1.2(46.2 \%)$ & $3(55.6 \%)$ \\
Hot Dry-IPSL-CM5A-MR RCP 8.5 & 20.8 & 22.2 & 24.9 \\
Warm Wet-CNRM-CM5 RCP 4.5 & 19.4 & & 19.6 \\
Warm Wet-GFDL-ESM2M RCP 4.5 & & & 19.5 \\
Warm Wet-INM-CM4 RCP 4.5 & & 2.6 & 5.4 \\
Individual-projection approach range & 1.4 & & 361.1 \\
(b) Precipitation (mm) & & 376.0 & 380.1 \\
RCP 8.5 & 369.6 & 371.5 & $19.0(7.4 \%)$ \\
RCP 4.5 & 369.1 & $4.5(2.8 \%)$ & 292.6 \\
RCP approach range & $0.5(0.4 \%)$ & 320.4 & 421.0 \\
Hot Dry & 334.3 & 414.9 & $128.4(50.0 \%)$ \\
Warm Wet & 416.9 & $94.5(58.5 \%)$ & 231.0 \\
Quadrant approach range & $82.6(67.9 \%)$ & 287.3 & \\
Hot Dry-IPSL-CM5A-MR RCP 8.5 & 294.2 & & 487.7 \\
Warm Wet-CNRM-CM5 RCP 4.5 & 415.9 & 448.9 & 256.7 \\
Warm Wet-GFDL-ESM2M RCP 4.5 & & & 161.5 \\
Warm Wet-INM-CM4 RCP 4.5 & 121.7 & & \\
Individual-projection approach range & & & \\
\hline
\end{tabular}

For each period (2040, 2060, and 2080), we identified two individual projections that are strongly divergent between the "Hot Dry" and "Warm Wet" CFs (circled projections in Fig. 3). One model (IPSL-CM5A-MR RCP 8.5) consistently represented a divergent "Hot Dry" CF (i.e., it occupied the farthest lower right portion of the "Hot Dry" sub-quadrant). For the "Warm Wet" CF, a different model was chosen to demonstrate maximal divergence in each period because of differences among projection dynamics through time (e.g., the "Warm Wet" projection chosen for 2080 is a "Warm Dry" projection in 2040). We present different projections across the three time periods to illustrate the broader range of uncertainty captured by the quadrant or individual-projection approaches over RCP-ensembles in discrete time periods (2040, 2060, 2080; Table 1, Fig. 3). However, in real-world applications, where we model resource response through time, we always maintain consistent projections. For example, to support the BBNP water development decision (Lawrence and Runyon 2019), our analysis consistently used INM-CM4 RCP 4.5 ("Warm Wet") and IPSL-CM5A-MR RCP 8.5 ("Hot Dry") because these were the most divergent projections during the late-century period (see circled projections in Fig. 3c). That period corresponded to the design life of the water redevelopment project (50-70 years, or 2070-2090). 
Differences in temperature and precipitation projections showed that the quadrant and individual-projection approaches captured a much greater proportion of the range of variation among projections than did RCP ensembles (Table 1). For example, the difference in annual average temperature between the individual-projection approach "Hot Dry" and "Warm Wet" CFs is $1.4{ }^{\circ} \mathrm{C}(2040), 2.6{ }^{\circ} \mathrm{C}(2060)$, and $5.4{ }^{\circ} \mathrm{C}(2080$; Table 1$)$. The difference for the same metric between an ensemble of models driven by RCP 8.5 and the same ensemble driven by RCP 4.5 is only $0.2{ }^{\circ} \mathrm{C}(2040), 0.7{ }^{\circ} \mathrm{C}(2060)$, and $1.9^{\circ} \mathrm{C}(2080)$, representing $14.3 \%, 26.9 \%$, and $35.2 \%$ of the range characterized by the individual-projection approach for each time period, respectively. Relative to the RCP approach, the quadrant approach captured a greater portion of the range represented by the individual-projection approach $(2040-64.3 \%$; 2060 $46.2 \%$; 2080-55.6\%). A similar, although exaggerated, phenomenon was observed for precipitation (Table 1). The divergence represented by quadrant-based CFs ("Hot Dry" vs "Warm Wet") was less than that represented using individual projections but greater than that produced using RCP ensembles (RCP 8.5 vs 4.5; Table 1). In the case of precipitation, RCP-based CFs capture a much smaller portion of the uncertainty relative to the other CF approaches (e.g., the RCP approach represents $0.4 \%, 2.8 \%$, and $7.4 \%$ of the range characterized by the individual-projection approach for each time period, respectively). Overall, the

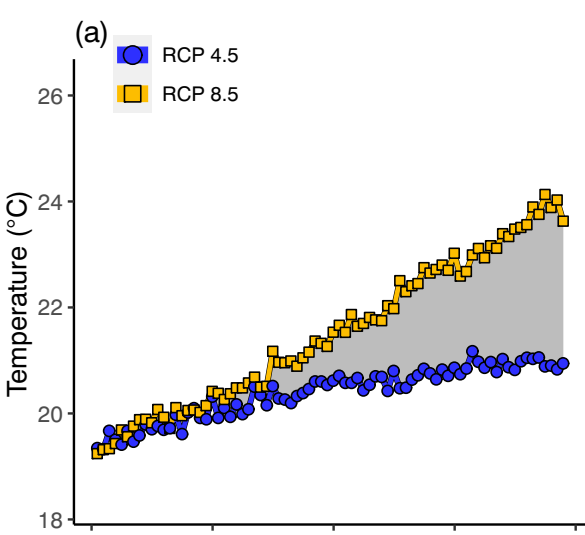

(c)

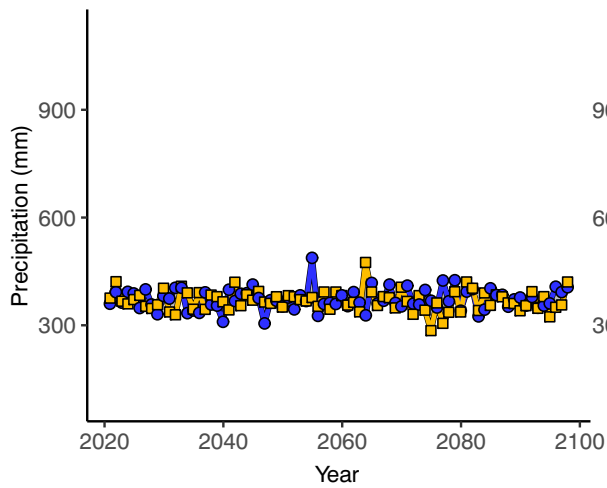

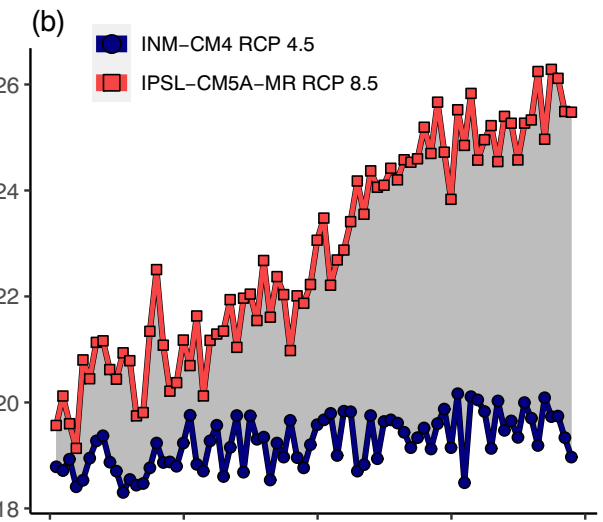

(d)

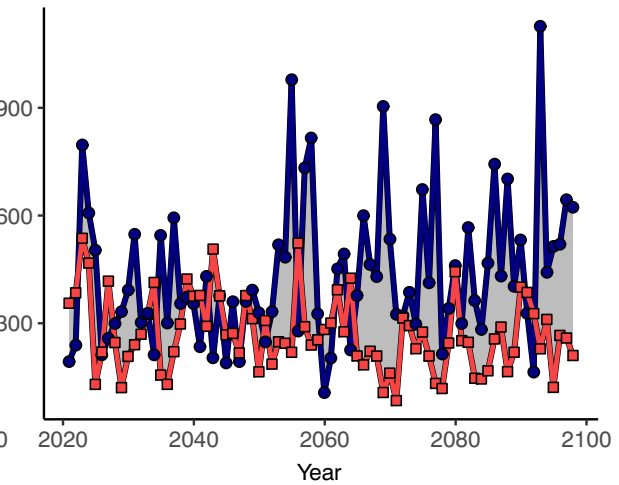

Fig. 4 Projected annual mean temperature from 2020 to 2100 for a RCP 4.5 and RCP 8.5 ensembles and b GCM-RCP projections INM-CM4 RCP 4.5 and IPSL-CM5A-MR RCP 8.5. Projected annual total precipitation from 2020 to 2100 for c RCP 4.5 and RCP 8.5 ensembles and d GCM-RCP projections INM-CM4 RCP 4.5 and IPSL-CM5A-MR RCP 8.5 
quadrant and especially the individual-projection approach support decision makers seeking to understand the broadest potential characterization of future conditions. The individualprojection approach seeks to provide an expansive characterization of the ways climate could plausibly change (i.e., using divergence to capture the greatest range in uncertainty), but as Mote et al. (2011) point out, even the large number of available projections does not represent the true physical uncertainty that many studies implicitly assume it does.

Differences in divergence between the RCP 8.5 and RCP 4.5 ensembles compared to "Warm Wet" and "Hot Dry" individual projections can be visualized using time series plots (Fig. 4). For consistency, we portray this comparison with the projections chosen for the 2080 period (IPSL-CM5A-MR RCP 8.5, INM-CM4 RCP4.5). Projections of temperature for the RCP 8.5 and RCP 4.5 ensemble increasingly diverge through time (Fig. 4a). This trend was not observed for precipitation (Fig. 4c), likely because averaging wetter and drier models in an ensemble results in less divergent precipitation projections. Individual projections chosen to represent "Hot Dry" and "Warm Wet" CFs increasingly diverge through time both in annual temperature and precipitation (Fig. 4b, d) but are also notably more divergent than RCP 4.5 and 8.5 ensembles in the near and long term.

Averaging within RCP ensembles mutes the temporal dynamics of climate metrics relative to individual projections (compare the interannual variability of Fig. $4 a$ to $4 b$, and $4 c$ to $4 d$ ). For resource managers, this variability, and associated change in frequency of extreme events, is often critical information for making long-term decisions that reduce the likelihood of future failure. In the BBNP case study, capturing this variability was essential given the key management metric we were evaluating: how often the groundwater-fed spring fell beneath a threshold flow. Snover et al. (2013) advise that when assessing effects sensitive to interannual variability, it is best to select a specific individual projection rather than using a multimodel average (or choose a method that preserves this variability).

CFs developed using the quadrant approach are not included in Fig. 4 because for some geographies (including BBNP) projections change sub-quadrants through time. Given these dynamics, we avoid, for example, plotting a "Warm Wet" quadrant-based CF annually, because the projections that make up that CF may be different from year to year (and therefore do not maintain internally consistent or coherent projection dynamics). This complexity is a limitation of this approach for investigating change through time, and because of this issue we generally only use quadrant-based CFs when planning for a single, discrete, time period (e.g., 2080).

\section{Considerations for climate future generation}

Many options exist for generating CFs, whether to support strategic planning or managing a specific resource. Below we discuss some of these considerations.

\subsection{Time period for climate futures and the number of climate periods}

The appropriate time period for CFs depends on the resource of interest, management question, and planning horizon. NPS planning horizons vary and are typically shorter for routine management (up to 30 years in the future; e.g., restoration, wildlife management), and 50 80 years for infrastructure (buildings, roads, etc.) or major wildlife investments (e.g., managed relocation, Karasov-Olson et al. 2021). 
Some management questions may require simultaneous evaluation of near- and long-term projections. For example, natural resource managers charged with native trout restoration in Yellowstone National Park may wish to evaluate stream temperature-relevant CFs in the near and long term to evaluate feasibility in both time frames. Evaluating strategies against near and long time frames can also help avoid maladaptation, where a decision to meet short-term goals precludes actions that are better in the long term (Noble et al. 2014). Our practice, when spanning multiple climate periods with individual projections, is to conduct the analysis using a consistent set of projections.

\subsection{Spatial resolution and extent for climate futures}

To create CFs, we currently use results from GCMs in the CMIP5 archive, statistically downscaled to $16 \mathrm{~km}^{2}$ using the MACA method (Abatzoglou and Brown 2012). Other downscaling options are available (Harris et al. 2014; Jiang et al. 2018) and the choice of downscaling method depends on the performance of different methods for representing the climate metrics of interest and the needed resolution. If warranted by the decision context, the spatial resolution (i.e., spatial grain) of a given set of CFs can be updated as finer-resolution downscaled models become available.

The spatial extent of data used to create CFs depends on the decisions of interest, input data, and available computing power. For parks with homogenous topography, we typically use a single grid cell from downscaled climate models to develop CFs for a given location. Multiple grid cells within a homogenous area can also be averaged to create CFs for a given spatial extent (e.g., an NPS park boundary). For spatial extents with heterogeneous topography and climates, we create multiple sets of CFs based on multiple grid cells spanning high- and lowelevation bands or locations that bracket other important climate gradients, such as wet/dry. Topography strongly affects local climate (Daly et al. 2008), and explicit consideration of topography is needed when selecting specific cells from gridded climate data in topographically rich terrain (Tercek et al. 2021). We also consult with management or resource experts to select cells that represent specific areas of interest. In the BBNP example, we chose to develop CFs for a grid cell overlying the recharge area of Oak Spring, rather than the grid cell overlying Oak Spring itself. This was a purposeful choice, because changing precipitation in the recharge area has the most direct (mechanistic) relationship to potential changes in Oak Spring discharge (Lawrence and Runyon 2019). Overall, researchers should be explicit that the intent of the chosen spatial coverage where CFs are developed is intended to be representative, informed by the management context, and any limitations and assumptions should be clearly reflected in how that information is used.

\subsection{Selecting metrics for climate futures}

CFs can be characterized by general metrics such as average annual temperature and total annual precipitation or by using climate metrics associated with specific resource sensitivities. In the BBNP application described above, contemporary precipitation was a key determinant of groundwater recharge so precipitation and air temperature were chosen as the climate metrics for defining CFs (Lawrence and Runyon 2019). Temperature was used for the second metric because it often affects water recharge dynamics by modifying evapotranspiration rates and the fluxes of water to the atmosphere and aquifer. 
In a different application, Devils Tower National Monument completed a strategic plan while considering the impacts of a suite of CFs on natural and cultural resources within the park (Schuurman et al. 2019). The primary climate change concerns for the park were increased degradation of historical structures, rock exfoliation of the tower, changes in vegetation composition and production, erosion, and visitor and staff safety. Climate metrics most closely associated with these concerns included (1) freeze-thaw cycles, (2) extremely hot days, (3) mean and maximum summer water deficit, and (4) $>1$-in. $(25.4 \mathrm{~mm})$ precipitation events (Schuurman et al. 2019). In this case, CFs were identified by plotting these four metrics relative to each other on individual bivariate scatter plots and identifying individual projections that were divergent across these climate axes. Alternatively, principle component analysis or other multivariate statistical techniques could be used to aid in the identification of divergent projections when considering multiple climate metrics (i.e., $\geq 2$ ) simultaneously, but CF selection will likely always involve some element of expert judgment that takes into account variable importance and the coherence of the resulting scenarios. Ultimately, in this case, four CFs were chosen based on individual projections. These CFs were used to identify potential impacts on the resources of interest through a participatory scenario planning workshop (see Section 5.5). In other situations, the relevant axes may include snow accumulation, days below freezing, or other climate metrics that strongly affect resources.

\subsection{Selecting the climate future approach and relevant climate futures}

The specific decision context or application typically determines the choice of CF approach (e.g., mitigation or adaptation emphasis, near- or long-term planning). For example, if the intent of the work is to examine consequences of different GHG mitigation efforts, then comparing high- and low-emissions CFs using the RCP approach is often suitable (HoeghGuldberg et al. 2018). If, on the other hand, the intent is to characterize the broadest range of potential future conditions to help a manager develop robust strategies and avoid catastrophic surprises, more divergent (or range-capturing) quadrant or individual-projection approaches are typically necessary. For near-term adaptation planning, the range of uncertainty represented by the RCP approach is particularly limited. The choice between quadrant and individualprojection approaches depends on details of the decision context. For example, if the planning effort focuses on temporal dynamics, we typically use individual projections because (as noted above) projections may move between different sub-quadrants through time (and therefore quadrant-based CFs do not maintain internally consistent or coherent model dynamics through time). We often use the quadrant approach as a coarse-filter evaluation of climate change, or for simpler planning processes, and use the individual-projection approach for detailed investigations (where the decision process provides more time for model choice and evaluation).

Choosing relevant CFs depends on the resources and geography of interest, among other considerations, and we rely on the experiential knowledge of local experts to understand the local context. For example, when examining vulnerability of forests to fire and drought in the arid southwest United States, contrasting a "Hot Dry" and "Warm Wet" CF is important. Similarly, in the eastern United States, comparing a "Warm Damp" and "Hot Wet" CF may be useful because most models project increasing precipitation and the effects of flooding, erosion, and mold development on NPS cultural resources are often a concern.

For NPS applications, we typically use two to four divergent CFs that bracket the range of climate uncertainty relevant to the resource-management decision of interest. CFs could be 
represented by a "best-/worst-case" situation, or "most/least change" contrast, which bracket high- to low-end changes in primary climate drivers (Snover et al. 2013). Brekke et al. (2009b) and Littell et al. (2011) describe using bracketed futures to connect climate uncertainty with risk tolerance. For example, risk-averse managers may plan for the most change, risk-tolerant managers the least change, and planning around an ensemble mean condition may be riskneutral. In broad planning efforts addressing a diversity of resources, it is often useful to consider more than two divergent CFs. However, the complexity of scenario planning increases rapidly as the number of CFs increases. From practical experience, there is an upper limit on the number of CFs an audience can reasonably consider during a planning effort (typically up to four; Schuurman et al. 2019).

\subsection{Translating climate futures into climate-resource scenarios}

The main reason for creating CFs is to anticipate how plausible climate changes may affect key resources. Resource implications (i.e., vulnerabilities) of a given CF can be assessed quantitatively and/or qualitatively in a participatory process that includes scientists, resource experts, and managers (e.g., Miller et al. 2017; Symstad et al. 2017). We refer to the range of resourcespecific effects driven by underlying CFs as divergent "climate-resource scenarios" (Fig. 1a; Miller et al. 2019; Runyon et al. 2020). Climate-resource scenarios inherit their divergence from the CFs, which form the template upon which the scenarios are described. We then use these climate-resource scenarios to evaluate the consequences of management actions under a variety of plausible, divergent, and challenging scenarios. By identifying the resource implications of different CFs, adaptation strategies can be developed to reduce the severity of these changes or capitalize on beneficial opportunities.

We generated "Hot Dry" and "Warm Wet" climate-resource scenarios of projected Oak Spring discharge to evaluate how often Oak Spring discharge may fall below 20 gpm in the future using the individual-projection approach, which captured the broadest range of plausible future conditions (Fig. 1b). To do so, we developed an empirical relationship between discharge and 2-month lagged precipitation, using historical data; then, we used the empirical relationship to estimate discharge from projected precipitation, based on divergent CFs (Lawrence and Runyon 2019). Under the "Hot Dry" climate-resource scenario, the times per decade Oak Spring fell below 20 gpm more than doubled compared to the historical period. Under the "Warm Wet" scenario, Oak Spring fell below $20 \mathrm{gpm}$ at a similar rate to the historical condition. Based on this information, local knowledge of current and potential future water requirements at the site, and considering the relative costs (and potential environmental harm) of switching to another water source, the park currently plans to re-develop Oak Spring as a water source, but will simultaneously (1) increase water conservation in the basin to reduce demand, (2) fix leaks in the plumbing to reduce significant water losses, and (3) add water storage to the system to help weather periods of hydrologic drought. Together, these actions are intended to make their investment in this long-lived water supply climate-informed and robust to even the "Hot Dry" scenario.

\section{Discussion}

Divergent and plausible CFs support decision makers' needs to consider the range of potential futures in their decision processes, avoid surprises, and avert maladaptation. Here, we describe 
CFs' application in the NPS, where we routinely use them to help managers engage in climateinformed management of natural and cultural resources, facilities, and human well-being and the visitor experience. In addition to the above case study, which demonstrates the use of CFs to support large-scale capital investment decision-making related to operations, we and our collaborators have applied CFs to multiple strategic planning efforts across these domains (NPS 2021). This includes standalone climate change scenario planning engagements with Knife River Indian Villages National Historic Site (Fisichelli et al. 2016a) and Badlands National Park (Fisichelli et al. 2016b; Miller et al. 2017; Miller et al. 2019), as well as projects that integrated climate science into NPS planning processes for Devils Tower National Monument (Schuurman et al. 2019) and Wind Cave National Park (Runyon et al. in press; Symstad et al. 2017). A key lesson from this range of experiences is that CFs can serve as fundamental climate change exposure information to aid simple to complex vulnerability assessments and adaptation more broadly (Runyon et al. 2020).

An overarching goal in using CFs is to explore the relevant uncertainty among projections of change. We do so by creating a tractable set of divergent CFs to characterize the range of potential future climatic conditions. CFs are often the precursor to climate-resource scenarios, where climate metrics - e.g., temperature, precipitation, water deficit-are linked to resources (e.g., forest composition) or processes of interest (e.g., fire, flood, recruitment). Because CFs are the building blocks of climate-resource scenarios, scenarios inherit the divergence of those futures. The benefit of this approach is two-fold. First, the CFs distill an overwhelming myriad of plausible climate projections into a manageable set. Second, a set of divergent, plausible, and relevant CFs support scenario-based planning that can identify resource management strategies that (1) work across all CFs (i.e., robust strategies), (2) do not work under any CF, and (3) are needed to address highly consequential vulnerabilities specific to a subset of the scenarios.

This work compared the divergence of CFs developed using three approaches for near-, mid-, and long-term projection time periods. The quadrant approach and the individualprojection approach capture a much broader range of plausible future conditions in both near- and long-term projections compared to the RCP approach. Choosing among these approaches to generate CFs ultimately depends on the application and available resources. Basing divergence on RCPs is useful for comparing how different levels of GHG-emissions mitigation influence the magnitude of climate change. For near-term adaptation planning where understanding the broadest range of plausible near-term climate outcomes is often desired, the quadrant and individual-projection approach may be better suited given their capacity to bracket this uncertainty. The individual-projection approach best captured the range of uncertainty in future conditions over all time periods. These highly divergent CFs facilitate planning to avoid costly and catastrophic "surprises" or lost opportunities that might arise from highly consequential climate or weather events. An important consequence of the projection-averaging approaches (i.e., RCP ensemble, quadrant average) is that the process of averaging results in loss of the underlying projection dynamics (e.g., interannual variability) and extremes, which are often important for estimating resource responses.

In contrast to some other CF generation processes (e.g., Whetton et al. 2012), for NPS applications, we generally do not evaluate the likelihood of each future (be it derived from the $\mathrm{RCP}$, quadrant, or individual-projection approach). Instead, we consider all CFs plausible for planning purposes. Other researchers use model weighting to account for skill and interdependence of models when averaging across models (Wootten et al. 2020). Although we see value in this approach, the computational requirements to correctly execute it would not be 
feasible for routine planning within the NPS. Our approach is consistent with the Intergovernmental Panel on Climate Change (IPCC), in that they do not assign probabilities to RCPs (van Vuuren et al. 2011), and with other scenario planning processes that expressly do not characterize scenarios in terms of relative likelihood (NAVFAC 2017; Rowland et al. 2014).

Scenario planning is founded on the concept that we do not know which future is most probable, but we can evaluate the appropriateness and consequences of strategies (e.g., goals and activities to achieve those goals) under each CF (i.e., wind tunneling; van der Merwe 2008). Identifying and planning for high-consequence (but potentially low-probability) futures is an important component of scenario planning, and contrasts with forecast planning intended to address a single most-likely future. As such, our overarching intent is to comprehensively consider potential ways the future may unfold, as opposed to trying to predict the probability of a specific future. In the same spirit, for the quadrant and individual-projection approaches, we often do not focus on the central tendency of the set of projections to describe one "most likely" future, but instead use the CFs to delimit the bounds of what is possible and then plan within that range. Indeed, Brekke et al. (2009a) highlight some of the challenges in attempting to derive probability distributions from climate projection information, and note "robustness" as an alternate criterion for planning versus "optimality alone," especially when trying to minimize the likelihood of surprises.

CFs produced by the approaches described here benefit planning efforts because they are (1) easy to communicate (e.g., audiences rapidly grasp concepts such as a "Warm Wet" or "Hot Dry" future), (2) easy to operationalize because practitioners can generate them using standard procedures, and (3) readily customized to accommodate characteristics of focal resources and geography. CFs can address any time period, or multiple time periods. Additionally, climate metrics that define CFs can be simple (temperature, precipitation) or complex (e.g., number of freeze-thaw cycles, growing season soil moisture). Users can choose to focus on two CFs (e.g., best/worst, most/least, hot/dry, etc.) or more if necessary.

A variety of organizations and agencies consider multiple CFs in scenario planning, and, like the NPS, are producing tools to streamline production of CFs and scenarios (e.g., BOR 2014; EPA 2020). The United States Forest Service has conducted an extensive evaluation to identify a subset of GCMs that are divergent, for use in scenario planning for forest management (Joyce and Coulson 2020; Langner et al. 2020). Cal-Adapt (https://cal-adapt.org/tools/) uses individual projections to define different CFs (i.e., warmer/drier, cooler/wetter, average, and compliment futures) to explore how climate change might affect California in terms of snowpack, extreme precipitation events, extreme heat days, and wildfire (Pierce et al. 2018). Additionally, the North Central Climate Adaptation Science Center, in collaboration with University of Colorado Boulder, has created an R package to facilitate development of CFs for a user-defined spatial area (https:/www.earthdatascience.org/cft/index.html). CSIRO's Representative Climate Futures Framework (Whetton et al. 2012) provides a tool to investigate how Australian climate projections cluster around two climate metrics and is intended to evaluate and illustrate the range of potential change and consensus of model projections.

Our approach to generating CFs is easily revised to reflect the rapidly evolving field of climate science. For example, an updated set of GCMs and emission pathways will be released soon as part of the IPCC sixth assessment report (i.e., CMIP6; Eyring et al. 2016). The CF approach can accept outputs from any GCM and emissions pathway as the raw data to generate CFs and so is readily adaptable to these sorts of updates. Additionally, the metrics we use to define CFs are not static and continue to evolve along with the decisions we seek to inform. 
Scenario planning has emerged as a widely used process for climate adaptation and more generally for resource management under uncertainty. CFs are a critical foundation for the scenario planning process, in that they describe the divergent futures that capture the range of changing climatic conditions that most impact resources. We described several approaches to generate CFs that support simple to highly detailed planning processes (spanning a range of low to high effort). Over the past decade, we have operationalized the generation of CFs, and the use of CFs to generate relevant climate-resource scenarios. Over that time, we have found CFs and climate-resource scenarios offer an efficient and adaptable approach to planning across a broad range of important management contexts.

Supplementary Information The online version contains supplementary material available at https://oi.org/ 10.1007/s10584-021-03169-y.

Acknowledgments We thank Amanda Carlson, Nicholas Fisichelli, Cat Hawkins Hoffman, Imtiaz Rangwala, Amy Symstad, and Leigh Welling for their contributions to the development and use of climate futures in resource management in the National Park Service (NPS). This study was improved by comments from Joel Reynolds, Gregg Garfin, and two anonymous reviewers. Climate future development has been supported by the NPS Climate Change Response Program. Any use of trade, firm, or product names is for descriptive purposes only and does not imply endorsement by the U.S. Government.

Code availability All scripts used to conduct this analysis and input files are accessible via the study's accompanying Zenodo database, https://doi.org/10.5281/zenodo.5139944.

Authors' contributions DJL, ANR, JEG, GWS, BWM devised the project and the main conceptual ideas. ANR and DJL conceived of and conducted the data analysis. DJL, ANR, JEG, GWS, BWM wrote the manuscript.

Funding Climate future development has been supported by the National Park Service Climate Change Response Program. A portion of this research was funded by the U.S. Geological Survey North Central Climate Adaptation Science Center.

Data availability The data used to support the findings in this study are the Multivariate Adaptive Constructed Analogs downscaled dataset, publicly available at MACA Statistical Downscaling Method (northwestknowledge.net).

\section{Declarations}

Conflicts of interest The authors declare no conflict of interest.

Open Access This article is licensed under a Creative Commons Attribution 4.0 International License, which permits use, sharing, adaptation, distribution and reproduction in any medium or format, as long as you give appropriate credit to the original author(s) and the source, provide a link to the Creative Commons licence, and indicate if changes were made. The images or other third party material in this article are included in the article's Creative Commons licence, unless indicated otherwise in a credit line to the material. If material is not included in the article's Creative Commons licence and your intended use is not permitted by statutory regulation or exceeds the permitted use, you will need to obtain permission directly from the copyright holder. To view a copy of this licence, visit http://creativecommons.org/licenses/by/4.0/. 


\section{References}

Abatzoglou JT, Brown TJ (2012) A comparison of statistical downscaling methods suited for wildfire applications. Int J Climatol 32:772-780

Albano CM, McCarthy MI, Dettinger MD, McAfee SA (2021) Techniques for constructing climate scenarios for stress test applications. Clim Chang 164:33

Battaglin W, Hay L, Lawrence DJ, McCabe G, Norton P (2020) Baseline conditions and projected future hydroclimatic change in national parks in the conterminous United States. Water 12:1704

Bock AR, McCabe GJ, Markstrom SL, Atkinson RD (2018) Do downscaled general circulation models reliably simulate historical climatic conditions? Earth Interact 22:1-22

BOR (2014) Hood River Basin study: climate change analysis technical memorandum. Bureau of Reclamation Pacific Northwest Regional Office, Boise, Idaho https:/www.usbr.gov/pn/studies/hoodriver/reports/ hrclimate.pdf. Accessed 11 Jun 2021

Brekke LD et al (2009a) Climate change and water resources management-a federal perspective: U.S. Geological Survey Circular 1331, $65 \mathrm{p}$

Brekke LD et al (2009b) Assessing reservoir operations risk under climate change. Water Resour Res 45: W04411

Brown C, Ghile Y, Laverty M, Li K (2012) Decision scaling: linking bottom-up vulnerability analysis with climate projections in the water sector. Water Resour Res 48:W09537

Carbone GJ (2014) Managing climate change scenarios for societal impact studies. Phys Geogr 35:22-49

Daly C et al (2008) Physiographically sensitive mapping of climatological temperature and precipitation across the conterminous United States. Int J Climatol 28:2031-2064

Dessai S, Hulme M, Lempert R, Pielke R (2009) Climate prediction: a limit to adaptation? Adapting to climate change: thresholds, values, governance. Cambridge University Press, Cambridge

EPA (2020) A Systematic Approach for Selecting Climate Projections to Inform Regional Impact Assessments. EPA/600/R-20/309. U.S. Environmental Protection Agency, Washington, D.C.

Eyring V et al (2016) Overview of the coupled model Intercomparison project phase 6 (CMIP6) experimental design and organization. Geosci Model Dev 9:1937-1958

Fisichelli NA et al (2016a) Resource management and operations in central South Dakota: climate change scenario planning workshop summary, Bismark, ND. Natural Resource Report. NPS/NRSS/NRR_-2016/ 1262. National Park Service. Fort Collins, Colorado. https://irma.nps.gov/DataStore/Reference/Profile/ 2230834

Fisichelli NA et al (2016b) Resource management and operations in southwest South Dakota: climate change scenario planning workshop summary, Rapid City, SD. Natural Resource Report. NPS/NRSS/NRR—2016/ 1289. National Park Service. Fort Collins, Colorado. https://irma.nps.gov/DataStore/Reference/Profile/ 2233058

Gross JE, Woodley S, Welling LA, Watson JEM (2016), Adapting to climate change: guidance for protected area managers and planners. Best practice protected area guidelines series no. 24. Gland, Switzerland: IUCN

Harris RMB et al (2014) Climate projections for ecologists. Wiley Interdiscip Rev-Clim Chang 5:621-637

Hawkins E, Sutton R (2009) The potential to narrow uncertainty in regional climate predictions. Bull Am Meteorol Soc 90:1095-1108

Hay LE, McCabe GJ (2019) A summary of CMIP3 and CMIP5 climate change projections for the conterminous U.S. 10.5066/P9V18TM9 Accessed 31 March 2021

Hoegh-Guldberg $\mathrm{O}$ et al (2018) Impacts of $1.5^{\circ} \mathrm{C}$ global warming on natural and human systems. In: MassonDelmotte $\mathrm{V}$ et al (eds) Global warming of $1.5^{\circ} \mathrm{C}$. An IPCC Special Report on the impacts of global warming of $1.5^{\circ} \mathrm{C}$ above pre-industrial levels and related global greenhouse gas emission pathways, in the context of strengthening the global response to the threat of climate change, sustainable development, and efforts to eradicate poverty. Cambridge University Press, Cambridge

IPCC (2013) Annex I: atlas of global and regional climate projections. In: van Oldenborgh GJ et al (eds) Climate change 2013: the physical science basis. Contribution of Working Group I to the Fifth Assessment Report of the Intergovernmental Panel on Climate Change. Cambridge University Press, Cambridge

Jantz P et al (2016) Potential impacts of climate change on vegetation for national parks in the eastern United States. In: Hansen AJ, Theobald DM, Monahan WB, Olliff ST (eds) Climate change in Wildlands: pioneering approaches to science and management. Island Press, Washington, D.C., pp 151-173

Jiang Y et al (2018) Inter-comparison of multiple statistically downscaled climate datasets for the Pacific Northwest, USA. Scientific Data 5:180016

Joyce LA, Coulson D (2020) Climate scenarios and projections: a technical document supporting the USDA Forest Service 2020 RPA Assessment. General Technical Report. RMRS-GTR-413. US Department of Agriculture, Forest Service, Rocky Mountain Research Station. Fort Collins, Colorado. 10.2737/RMRSGTR-413 
Karasov-Olson A et al (2021) Ecological risk assessment of managed relocation as a climate change adaptation strategy. Natural Resource Report. NPS/NRSS/CCRP/NRR-2021/2241. National Park Service, Fort Collins, Colorado. https://irma.nps.gov/DataStore/Reference/Profile/2284919

Karmalkar AV, Thibeault JM, Bryan AM, Seth A (2019) Identifying credible and diverse GCMs for regional climate change studies-case study: Northeastern United States. Clim Chang 154:367-386

Kirtman B et al (2013) Chapter 11: near-term climate change: projections and predictability. In: Stocker TF et al (eds) Climate change 2013: the physical science basis. Cambridge University Press, Cambridge

Kopp RE et al (2017) Potential surprises - compound extremes and tipping elements. In: Wuebbles DJ et al (eds) Climate science special report: Fourth National Climate Assessment, US Global Change Research Program, vol I. Washington, D.C., pp 411-429

Langner LL et al (2020) Future scenarios: a technical document supporting the USDA Forest Service 2020 RPA Assessment. General Technical Report. RMRS-GTR-412. US Department of Agriculture, Forest Service, Rocky Mountain Research Station. Fort Collins, Colorado. 10.2737/RMRS-GTR-412

Lawrence DJ, Runyon AN (2019) Implications of climate change for the water supply of the Chisos Mountains developed area: Big Bend National Park technical assistance request 4945. Natural Resource Report. NPS/ NRSS/CCRP/NRR—2019/2045. National Park Service, Fort Collins, Colorado. https://irma.nps.gov/ DataStore/Reference/Profile/2267489

Lempert RJ, Popper SW, Bankes SC (2003) Shaping the next one hundred years: new methods for quantitative. Long-Term Policy Analysis RAND Corporation. https://doi.org/10.7249/MR1626

Littell JS, McKenzie D, Kerns BK, Cushman S, Shaw CG (2011) Managing uncertainty in climate-driven ecological models to inform adaptation to climate change. Ecosphere 2:102

Maloney KO et al (2020) Disentangling the potential effects of land-use and climate change on stream conditions. Glob Chang Biol:2251-2269

Miller BW, Symstad AJ, Frid L, Fisichelli NA, Schuurman GW (2017) Co-producing simulation models to inform resource management: a case study from southwest South Dakota. Ecosphere 8:e02020

Miller BW, Symstad AJ, Schuurman GW (2019) Implications of climate scenarios for Badlands National Park resource management. NPS Climate Change Response Program project and park-specific briefs https:// www.nps.gov/badl/upload/BADL_Climate_Scenarios_Brief.pdf. Accessed 28 Oct 2020

Monahan WB, Cook T, Melton F, Connor J, Bobowski B (2013) Forecasting distributional responses of limber pine to climate change at management-relevant scales in Rocky Mountain National Park. PLoS One 8: e83163

Moss RH et al (2010) The next generation of scenarios for climate change research and assessment. Nature 463: $747-756$

Mote P, Brekke L, Duffy PB, Maurer E (2011) Guidelines for constructing climate scenarios. EOS Trans Am Geophys Union 92:257-258

NAVFAC (2017) Naval facilities engineering command installation adaptation and resilience climate change planning handbook. https://www.fedcenter.gov/_kd/go.cfm?destination=ShowItem\&Item_ID=31041. Accessed 31 Mar 2021

Noble IR et al (2014) Chapter 14: adaptation needs and options. In: Field CB et al (eds) Climate change 2014: impacts, adaptation, and vulnerability. Part A: global and sectoral aspects. Contribution of Working Group II to the Fifth Assessment Report of the Intergovernmental Panel on Climate Change. Cambridge University Press, Cambridge

NPS (2021) Climate change scenario showcase. National Park Service, Fort Collins, Colorado. Available at: https://www.nps.gov/subjects/climatechange/scenarioplanning.htm Accessed 23 Jun 2021

Peterson GD, Cumming GS, Carpenter SR (2003) Scenario planning: a tool for conservation in an uncertain world. Conserv Biol 17:358-366

Pierce DW, Kalansky JF, Cayan DR (2018) Climate, drought, and sea level rise scenarios for the fourth California climate assessment. California's fourth climate change assessment, California Energy Commission. Publication Number: CNRA-CEC-2018-006

Rasmussen BK et al (2015) Integrating climate change in transportation and land use scenario planning: an example from central New Mexico. DOT-VNTSC-FHWA-15-10. US Department of Transportation. John A Volpe National Transportation Systems Center

Rowland ER, Cross MS, Hartmann H (2014) Considering multiple futures: scenario planning to address uncertainty in natural resource conservation. Washington, D.C., US Fish and Wildlife Service

Runyon AN, Carlson AR, Gross JE, Lawrence DJ, Schuurman GW (2020) Repeatable approaches to work with scientific uncertainty and advance climate change adaptation in US national parks. Parks Stewardship Forum 36:98-104

Runyon AN, Schuurman GW, Miller BW, Symstad AJ, Hardy AR (In press) Climate change scenario planning for resource stewardship at Wind Cave National Park.Natural Resource Report. NPS/NRSS/NRR—2021. National Park Service, Fort Collins, Colorado 
Rupp DE, Abatzoglou JT, Hegewisch KC, Mote PW (2013) Evaluation of CMIP5 20th century climate simulations for the Pacific Northwest USA. J Geophys Res-Atmos 118:10884-10906

Ryan SJ, Lippi CA, Zermoglio F (2020) Shifting transmission risk for malaria in Africa with climate change: a framework for planning and intervention. Malar J 19:170

Schuurman GW, Symstad A, Miller BW, Runyon AN, Ohms R (2019) Climate change scenario planning for resource stewardship: applying a novel approach in Devils Tower National Monument. Natural Resource Report. NPS/NRSS/CCRP/NRR - 2019/2052. National Park Service, Fort Collins, Colorado. https://irma. nps.gov/DataStore/DownloadFile/632857

Sheffield J et al (2013a) North American climate in CMIP5 experiments. Part I: evaluation of historical simulations of continental and regional climatology. J Clim 26:9209-9245

Sheffield J et al (2013b) North American climate in CMIP5 experiments. Part II: evaluation of historical simulations of intraseasonal to decadal variability. J Clim 26:9247-9290

Snover AK et al (2013) Choosing and using climate-change scenarios for ecological-impact assessments and conservation decisions. Conserv Biol 27:1147-1157

Star J et al (2016) Supporting adaptation decisions through scenario planning: enabling the effective use of multiple methods. Clim Risk Manag 13:88-94

Symstad AJ, Fisichelli NA, Miller BW, Rowland E, Schuurman GW (2017) Multiple methods for multiple futures: integrating qualitative scenario planning and quantitative simulation modeling for natural resource decision making. Clim Risk Manag 17:78-91

Taylor KE, Stouffer RJ, Meehl GA (2012) An overview of CMIP5 and the experiment design. Bull Am Meteorol Soc 93:485-498

Terando A et al (2020) Using information from global climate models to inform policymaking - the role of the U.S. Geological Survey: U.S. Geological Survey Open-File Report 2020-1058. https://doi.org/10.3133/ ofr20201058

Tercek MT et al (2021) Correctly applying lapse rates in ecological studies: comparing temperature observations and gridded data in Yellowstone. Ecosphere 12:e03451

USGCRP (2018) Impacts, risks, and adaptation in the United States: Fourth National Climate Assessment, Volume II. In: Reidmiller DR et al (eds) US Global Change Research Program, Washington, DC, 1515 pp

van der Merwe L (2008) Scenario-based strategy in practice: a framework. Adv Dev Hum Resour 10:216-239

van Hooidonk R, Maynard JA, Liu Y, Lee SK (2015) Downscaled projections of Caribbean coral bleaching that can inform conservation planning. Glob Chang Biol 21:3389-3401

van Vuuren DP et al (2011) The representative concentration pathways: an overview. Clim Chang 109:5-31

Whetton P, Hennessy K, Clarke J, McInnes K, Kent D (2012) Use of representative climate futures in impact and adaptation assessment. Clim Chang 115:433-442

Whitlock C, Cross W, Maxwell B, Silverman N, Wade AA (2017) 2017 Montana climate assessment. Bozeman and Missoula MT: Montana State University and University of Montana, Montana Institute on Ecosystems, p 318. https://doi.org/10.15788/m2ww8w

Wootten AM, Massoud EC, Sengupta A, Waliser DE, Lee H (2020) The effect of statistical downscaling on the weighting of multi-model ensembles of precipitation. Climate 8:138

Publisher's note Springer Nature remains neutral with regard to jurisdictional claims in published maps and institutional affiliations. 